\title{
Fractional differential inclusions with multi-point boundary conditions involving Hilfer-Hadamard derivative
}

\author{
Benaouda HEDIA ${ }^{1}$, Berrrabah Fatima ${ }^{2}$, and Gisèle Mophou ${ }^{3}$ \\ ${ }^{1}$ University of Tiaret \\ ${ }^{2}$ Université Oran1 \\ ${ }^{3}$ Université des Antilles
}

January 17, 2022

\begin{abstract}
In this paper, we studied the existence and uniqueness result of solutions for boundary value problems for Hilfer-Hadamard type fractional differential inclusions with multi-point boundary conditions, in the first approach we deal with a non-convex valued right hand side and in the second approach we consider the Carath \'eodory case. Finally the compactness of solution sets is also obtained.
\end{abstract}

\section{Hosted file}

Hedia-Berrabah-MMAS-2022.pdf available at https://authorea.com/users/455723/articles/552997fractional-differential-inclusions-with-multi-point-boundary-conditions-involvinghilfer-hadamard-derivative

\section{Hosted file}

Hedia-Berrabah-MMAS-2022.tex available at https://authorea.com/users/455723/articles/552997fractional-differential-inclusions-with-multi-point-boundary-conditions-involvinghilfer-hadamard-derivative 